\title{
ITEM ANALYSIS BLOK IMUNOLOGI DAN NEOPLASMA TA 2015-2016 DI PROGRAM STUDI PENDIDIKAN DOKTER UNIVERSITAS MALIKUSSALEH
}

\author{
Sri Wahyuni* \\ Bagian Biokimia Fakultas Kedokteran Universitas Malikussaleh, \\ Lhokseumawe-Aceh, 24351, Indonesia \\ *Corresponding Author: sri.wahyuni@unimal.ac.id
}

\begin{abstract}
Abstrak
Multiple-choice questions (MCQs) atau soal pilihan berganda sering digunakan dalam penilaian mahasiswa. Item analysis secara luas digunakan untuk memperbaiki kualitas ujian. Indeks kesulitan soal (p) dan indeks diskriminasi soal (D) adalah dua indikator objektif untuk evaluasi soal MCQ. Penelitian ini bertujuan untuk menilai kualitas soal dan menjadikan soal yang berkualitas sebagai bank soal. Sebanyak 70 soal MCQ Blok Imunologi dan Neoplasma dianalisis dan dihitung nilai $\mathrm{p}$ dan nilai $\mathrm{D}$ masing-masing soal menggunakan Microsoft Excel. Korelasi antara p dan D dianalisis menggunakan korelasi Pearson. Hasil penelitian menunjukkan rerata nilai mahasiswa adalah $33,5 \pm 10,3$. Rerata nilai p adalah $0.48 \pm 0.21$ dan rerata nilai $D$ adalah $0.37 \pm 0.23$. Sebanyak $13(19 \%)$ soal termasuk mudah, $15(21 \%)$ soal termasuk sulit dan $42(60 \%)$ masih acceptable. Sebanyak masing-masing 3 (4\%) soal mempunyai nilai indeks diskriminasi negatif dan rendah (poor). Total 79\% soal memiliki indeks diskriminasi acceptable-excellent. Indeks diskriminasi menunjukkan korelasi positif lemah dengan indeks kesulitan soal $(r=0,357)$ dan bermakna signifikan $(p=0,02)$. Penelitian ini menyimpulkan bahwa soal MCQ sudah mempunyai kualitas yang baik dan dapat dipergunakan pada ujian selanjutnya sehingga memperbaiki kualitas ujian secara keseluruhan.
\end{abstract}

Kata Kunci : indeks kesulitan soal; indeks diskriminasi soal; item analysis; multiple choice question; $M C Q$ 


\title{
AN ITEM ANALYSIS OF MULTIPLE-CHOICE QUESTIONS OF IMMUNOLOGY AND NEOPLASMA BLOCK IN THE ACADEMIC YEAR 2015-2016 AT FACULTY OF MEDICINE UNIVERSITAS MALIKUSSALEH
}

\begin{abstract}
Multiple-choice questions (MCQs) are widely used in student assessment. Item analysis is widely used to improve test quality through knowledge about item statistic. Difficulty and discriminatory indices are two objective ways of demonstrating the concept and widely used in the evaluation of MCQ. The aim of the study was to assess the quality of MCQs, for creating a viable question bank for future use. The present study is a cross-sectional study. A test of 70 items was used for data collection. The MCQs were analyzed for difficulty index (p-value) and discrimination index (D). The data was analyzed by Microsoft Excel. The relationship between the difficulty index (p) and discrimination index (D) for each test item was determined by Pearson correlation analysis. Mean p-value and Dvalue were $0.48 \pm 0.21$ and $0.37 \pm 0.23$, respectively. On an average, about $13(19 \%)$ of the MCQs were too easy while 15 (21\%) were difficult and the remaining 42 $(60 \%)$ items were in acceptable range. In all, $3(4 \%)$ items showed negative discrimination and poor discrimination. The remaining $79 \%$ of the items were in the range of acceptable to excellent discrimination. The discrimination index exhibited slight positive correlation with difficulty index $(r=0.357 ; p=0.02)$ and statistically significant. The majority $(79 \%)$ of the items was acceptable as far as difficulty and discriminative indices were concerned. This study inferred that items having average difficulty and high discriminating index should be incorporated into future tests to improve the test development and review.
\end{abstract}

Keywords: difficulty index; discrimination index; item analysis; multiple choice questions; MCQs 


\section{Pendahuluan}

Evaluasi merupakan komponen penting dalam kurikulum pembelajaran. Evaluasi pengetahuan dianggap sebagai komponen esensial dalam pendidikan kedokteran dan salah satunya dilakukan melalui ujian tertulis menggunakan Multiple Choice Questions (MCQ). Multiple choice questions (MCQS) digunakan sebagai alat evaluasi yang objektif dan reliabel untuk menilai performa belajar mahasiswa. Soal MCQ yang disusun dengan baik mampu menilai proses kognitif yang tinggi menurut Taksonomi Bloom seperti interpretasi, sintesis dan aplikasi pengetahuan dibandingkan hanya menilai testing recall. ${ }^{1}$ Meningkatnya penggunaaan ujian tertulis MCQ karena memiliki obyektifitas tinggi dan mudah dalam analisis serta pelaporan. Konstruksi dari MCQ yang berkualitas baik untuk menilai kemampuan analisis, problem solving dan kemampuan kognitif lainnya merupakan suatu tantangan namun penting untuk dipahami. ${ }^{2}$

Item analysis secara luas digunakan untuk memperbaiki kualitas ujian secara statistik. Analisis ini memungkinkan untuk menilai karakteristik dari soal dan dapat digunakan untuk memastikan bahwa soal sudah sesuai standar ujian. ${ }^{2}$ Kualitas soal yang baik dapat dinilai dengan menggunakan indeks kesulitan dan indeks diskriminasi soal. Kedua indeks ini merupakan 2 metode obyektif untuk evaluasi soal MCQ. Indeks kesulitan soal (Difficulty index) menunjukkan seberapa sulit atau mudahnya suatu soal ujian untuk dijawab dengan benar. Sedangkan nilai indeks diskriminasi soal adalah seberapa baik suatu soal ujian membedakan antara mahasiswa yang yang sudah benar-benar memahami pelajaran dengan baik dengan mahasiswa yang memahami secara belum sempurna. Tujuan utama dari item analysis adalah memperbaiki ujian dengan merevisi atau mengeliminasi soal-soal ujian yang tidak efektif. ${ }^{4}$ Penelitian ini bertujuan untuk menentukan nilai indeks diskriminasi, indeks kesulitan soal dan menilai kualitas soal MCQ yang digunakan dalam ujian Blok Imunologi dan Neoplasma pada tahun akademik 2015-2016 di Prodi Pendidikan Dokter Universitas Malikussaleh.

\section{Metode}

Penelitian potong lintang (crosssectional) ini mengambil data 70 soal MCQ dari Blok Imunologi dan Neoplasma pada kurikulum Prodi Pendidikan Dokter Tahun Akademik 2015-2016. Skor total mahasiswa yang ikut ujian diurutkan dari nilai tertinggi (Upper group) hingga terendah (Lower group), jika ada skor yang sama diurutkan sesuai abjad nama mahasiswa kemudian 25\% atau 16 orang skor mahasiswa tertinggi dan terendah dipilih untuk dianalisis menggunakan Microsoft Excel. Selanjutnya, dihitung jumlah jawaban yang benar dari masing-masing kelompok untuk menentukan indeks diskriminasi dan indeks kesulitan soal. Analisis korelasi Pearson digunakan untuk menentukan korelasi antara indeks diskriminasi dan indeks kesulitan soal.

1. Indeks kesulitan / Difficulty index (p): menunjukkan seberapa sulit atau mudahnya sebuah soal ujian dijawab. Indeks ini didapat dari proporsi antara jumlah mahasiswa yang menjawab benar dengan jumlah total mahasiswa yang ikut ujian. Nilai ini dituliskan sebagai persen dan disebut juga nilai $\mathrm{p}$. Formula berikut digunakan untuk menentukan tingkat kesulitan. ${ }^{4}$

$$
\mathrm{p}=\mathrm{Ru}+\mathrm{Rl} / \mathrm{Nu}+\mathrm{Nl} \times 100
$$

Dimana

$\mathrm{Ru}=$ jumlah jawaban benar pada upper group

$\mathrm{Rl}=$ jumlah jawaban benar pada lower group

$\mathrm{Nu}=$ jumlah mahasiswa pada upper group

$\mathrm{Nl}=$ jumlah mahasiswa pada lower group 
Nilai indeks kesulitan atau $\mathrm{p}$ berkisar antara $0 \mathrm{~s} / \mathrm{d} 1$. Apabila dikalikan 100 (persen), maka nilai $\mathrm{p}$ menunjukkan persentase mahasiswa yang menjawab soal dengan benar. Makin tinggi nilai $p$, maka makin mudah suatu soal. Indeks kesulitan soal dikategorikan: < 0,30 (sulit), 0,30 - 0,70 (mudah), > 0,70 (sangat mudah)..$^{5}$

2. Indeks diskriminasi / Discrimination index (D): Menentukan seberapa baik soal mendiferensiasi antara mahasiswa yang yang sudah benar-benar memahami pelajaran dengan baik (knowledgeable students) dengan mahasiswa yang memahami secara belum sempurna (mediocre students). ${ }^{6}$ Indeks diskriminasi dihitung dengan cara sebagai berikut:

$$
\mathrm{D}=2 \times \mathrm{H}-\mathrm{L} / \mathrm{N}
$$

Dimana,

$\mathrm{H}=$ jumlah jawaban benar pada upper group $\mathrm{L}=$ jumlah jawaban benar pada lower group $\mathrm{N}=$ jumlah total mahasiswa kedua kelompok

Nilai indeks diskriminasi soal berkisar $1,00 \mathrm{~s} / \mathrm{d} 1,00$. Semakin tinggi nilai $\mathrm{D}$, maka makin efektif sebuah soal ujian. Nilai $\mathrm{D}=1$ menunjukkan bahwa semua mahasiswa pada upper group dan tidak ada mahasiswa pada lower group yang menjawab dengan benar. Sebaliknya, jika D negatif berarti tidak ada satupun mahasiswa upper group, tetapi semua mahasiswa pada lower group menjawab soal dengan benar. ${ }^{7}$ Indeks diskriminasi diklasifikasikan ke dalam 5 kategori: negatif (Defective items/Wrong key), 0,2-0,29 (Acceptable), 0,20-0,29 (Good), 0,300,39 (Good), dan $\geq 0,4$ (Excellent). ${ }^{8}$

\section{Hasil Penelitian}

\section{Indeks Kesulitan Soal/ Difficulty index}

\section{(p)}

Rerata nilai indeks kesulitan soal (p) adalah $0,48 \pm 0,21$. Rentang nilai indeks kesulitan soal cukup besar yaitu 0,06
0,84. Berdasarkan kriteria Indeks kesulitan soal (p), masing-masing soal ujian dikelompokkan dalam 3 kategori seperti ditunjukkan dalam Gambar 1. Sebanyak 60\% (42 soal) mempunyai indeks kesulitan mudah (acceptable), 19\% (13 soal) sangat mudah dan $21 \%$ (15 soal) sulit.

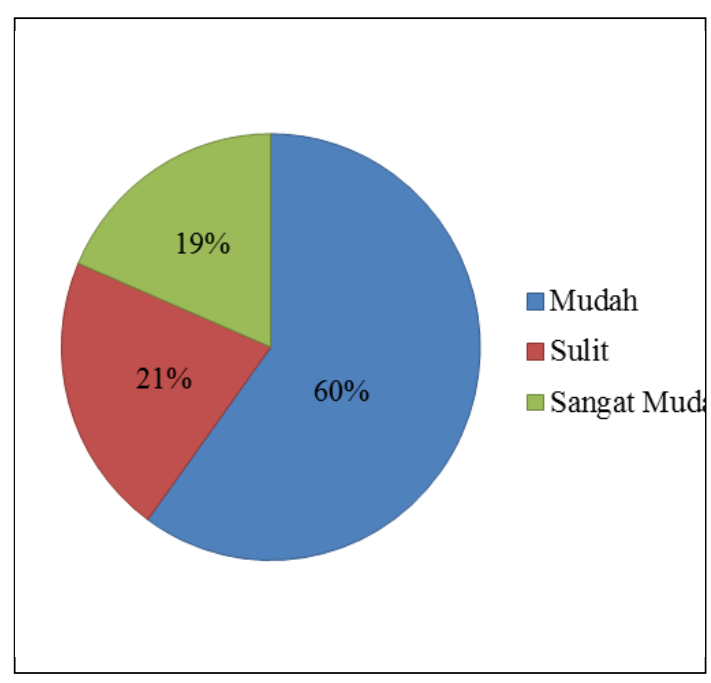

\section{Gambar 1. Distribusi soal berdasarkan nilai indeks kesulitan (p)}

\section{Indeks Diskriminasi soal/}

Discrimination index (D)

Rerata nilai indeks diskriminasi (D) adalah 0,37 $\pm 0,23$ dengan rentang nilai $-0,25-0,93$. Berdasarkan kriteria Indeks diskriminasi (D), masing-masing soal ujian dikelompokkan dalam 5 kategori seperti ditunjukkan dalam Gambar 2. Sebanyak 4\% (3 soal) yang memiliki indeks diskriminasi negatif (defective items), 17\% (12 soal) Poor, 4\% (3 soal) Acceptable, 26\% Good (18 soal) dan 49\% (34 soal) Excellent. 


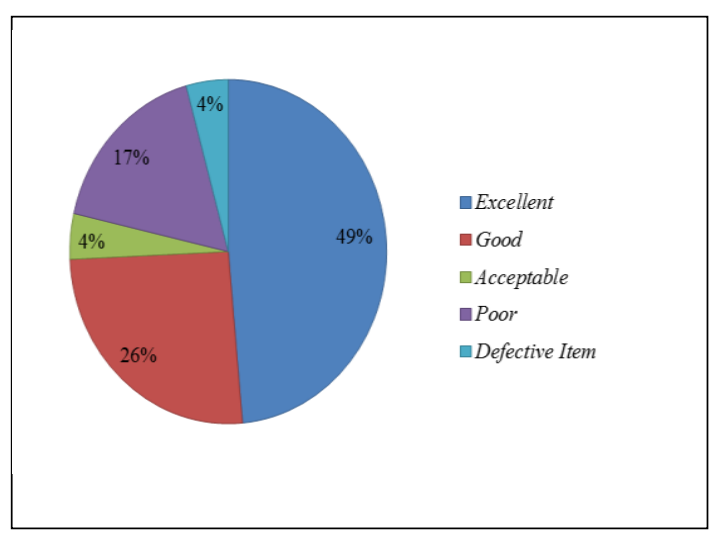

Gambar 2. Distribusi soal berdasarkan nilai indeks diskriminasi (D)

3. Korelasi nilai indeks kesulitan dan indeks diskriminasi soal

Uji korelasi Pearson antara nilai indeks kesulitan dan indeks diskriminasi soal ditampilkan pada Gambar 3. Diagram sebar (scatter diagram) menunjukkan korelasi antara nilai $\mathrm{p}$ dan $\mathrm{D}$ dari 70 soal MCQ. Indeks diskriminasi berkorelasi positif dengan indeks kesulitan soal dan bermakna signifikan secara statistik ( $\mathrm{r}=$ 0,357, $p=0,02)$. Sementara itu, 3 soal yang memiliki nilai indeks diskriminasi negatif masing-masing mempunyai rentang indeks kesulitan 0,09-0,25 atau tergolong sulit.

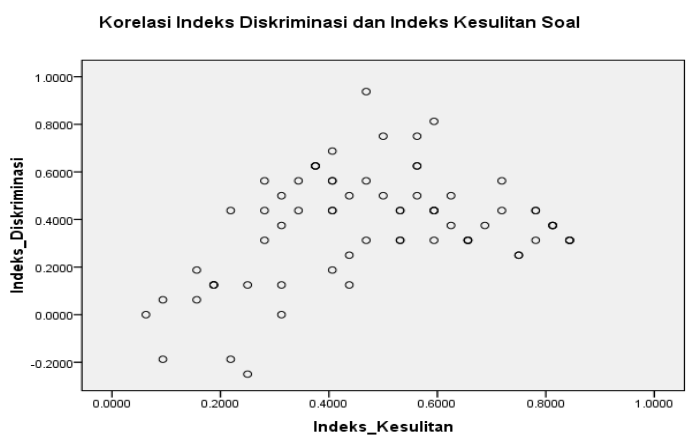

Gambar 3. Korelasi nilai indeks diskriminasi dan indeks kesulitan soal

\section{Pembahasan}

Rerata nilai ujian yang diperoleh oleh total 63 mahasiswa yang ikut ujian Blok Imunologi dan Neoplasma adalah 33,5 \pm
10,3. Nilai ujian berdasarkan kelompok yaitu 46,4 $\pm 4,7$ (upper group) dan 20,2 $\pm 2,6$ (lower group). Rerata nilai indeks kesulitan soal (p) pada penelitian ini adalah 0,48 \pm 0,21 . Nilai $p$ ini berarti bahwa $48 \%$ mahasiswa yang menjawab soal tersebut dengan dengan benar atau sebesar $48 \%$ soal ujian masih termasuk mudah atau acceptable. Semakin besar nilai $\mathrm{p}$, maka semakin mudah soal ujian tersebut.

Peneliti lain menemukan nilai rerata indeks kesulitan soal adalah $39.4 \pm 21.4 \%$ dan $52.53 \pm 20.59 \% .8$ Sebuah studi yang dilakukan selama periode 5 tahun menemukan rata-rata indeks diskriminasi soal $47.17 \pm 19.77$ sampai $58.08 \pm 19.33 .^{10}$ Studi lain melaporkan hasil yang sama bahwa $62 \%$ soal mempunyai nilai p yang acceptable $(30-70 \%), 23 \%$ soal terlalu mudah ( $p>70 \%)$, serta $15 \%$ sulit $(\mathrm{p}<30 \%) .{ }^{8}$ Hasil penelitian di Smt. NHL Municipal Medical College, Ahmedabad melaporkan $80 \%$ soal berkriteria acceptable (p 30-70\%) and 20\% unacceptable ( $\mathrm{p}>70 \% \quad \& \quad<30 \%) .{ }^{11}$ Hasil penelitian serupa juga menunjukkan bahwa 40\% MCQ termasuk mudah, 20\% sangat mudah dan 2\% termasuk soal MCQ yang sulit. ${ }^{12}$ Pada penelitian ini terdapat $21 \%$ soal ujian MCQ yang mempunyai kriteria indeks kesulitan < 0,3 yang mengindikasikan soal ujian tersebut relatif sulit. Sebanyak 60\% soal memiliki indeks kesulitan yang acceptable dan direkomendasikan disimpan dalam bank soal, sedangkan $40 \%$ soal dengan indeks kesulitan terlalu mudah dan sulit harus direvisi.

Indeks kesulitan soal sangat kecil ( $p<$ 0,3) atau termasuk soal sulit mengindikasikan bahwa materi ujian tersebut tidak diajarkan mendalam atau terlalu sulit dipahami oleh mahasiswa. Hal ini juga menunjukkan bahwa topik yang diujiankan tidak sesuai dengan level mahasiswa. ${ }^{6}$ Variasi ini kemungkinan disebabkan oleh kurangnya pemahaman terhadap topik yang sulit, ambigu dalam membuat pertanyaan atau kunci jawaban 
yang tidak tepat serta variasi personal dalam membuat soal MCQ atau beragamnya tingkat kecerdasan mahasiswa. Suatu ujian diharuskan mempunyai tingkat kesulitan yang bervariasi untuk membedakan antara mahasiswa yang tidak memiliki kesiapan menghadapi ujian, mahasiswa yang cukup siap dan mahasiswa yang memiliki kesiapan sangat baik dalam menghadapi ujian. Oleh karena itu, soal ujian dituntut memiliki tingkat kesulitan yang beragam. ${ }^{13}$

Rerata nilai indeks diskriminasi dari 70 soal yang diteliti adalah 0,37 dan nilai ini sudah memenuhi rentang yang dianjurkan oleh peneliti lain. ${ }^{14}$. Sebanyak $49 \%$ soal memiliki indeks diskriminasi $>0,4$ atau merupakan diskriminator yang sangat baik (excellent). Hasil ini menunjukkan sebanyak 49\% mahasiswa mampu menjawab soal tersebut dengan benar. Studi di Fakultas Kedokteran Gigi di Pakistan menunjukkan $62 \%$ soal yang dibuat memiliki indeks diskriminasi excellent. ${ }^{15}$

Meskipun begitu, terdapat 4\% (3 soal) ujian yang mempunyai indeks diskriminasi negatif atau mendekati nol dan $12 \%$ memiliki indeks diskriminasi rendah ( $\mathrm{D}<$ $0,19)$. Soal ujian sejenis ini tidak dapat membedakan mahasiswa yang paham secara sempurna dengan yang belum paham serta tidak dihitung sebagai variasi soal ujian yang sesungguhnya. Defective items atau soal dengan indeks diskriminasi negatif ditemukan pada 3 soal MCQ dan hasil ini dapat pula dipengaruhi oleh kesiapan mahasiswa menghadapi ujian. Hasil yang sama juga didapatkan pada analisis ujian obstetrik dan ginekologi mahasiswa preklinik yaitu $38 \%$ soal ujian memiliki nilai $\mathrm{D}<0,2$ dan 23 soal diantaranya memiliki koefisien diskriminasi negatif. Soal dengan indeks diskriminasi negatif merupakan defective items dan harus dihilangkan, sedangkan soal ujian diskriminator rendah mutlak harus direvisi secara menyeluruh. ${ }^{5}$
Kekuatan diskriminasi rendah mungkin menunjukkan soal yang membingungkan seperti ambigu kata-kata dalam soal atau mengindikasikan salah kunci jawaban. Penyebab indeks diskriminasi soal bernilai negatif adalah mahasiswa dalam lower group seringkali menerka jawaban dari soal yang mudah dan biasanya terkaan tersebut benar. Hal ini kontradiksi dengan mahasiswa upper group yaitu mahasiswa terlalu waspada terhadap soal yang mudah dan akhirnya memilih jawaban yang salah. Soal ujian dengan koefisien diskriminasi negatif harus dihilangkan dari bank soal. Hal ini dikarenakan soal tersebut mengindikasikan mahasiswa dalam kelompok lower group menjawab benar dan mahasiswa kelompok upper malah salah menjawab soal tersebut. ${ }^{16}$ Nilai indeks diskriminasi maksimum (D = 0,94) memiliki indeks kesulitan 0,47 yang berarti soal mudah dan memiliki kekuatan diskriminasi yang sangat baik (excellent). Soal yang sangat mudah atau sangat sulit memiliki kekuatan diskriminasi yang rendah (poor). Apabila tiap soal dianalisis berdasarkan kedua indeks tersebut, maka terdapat total 38 soal ujian yang dapat direkomendasikan sebagai bank soal.

Korelasi antara indeks diskriminasi dan indeks kesulitan soal pada penelitian ini adalah korelasi positif $(\mathrm{r}=0,357, \mathrm{p}=0,02<$ $0,05)$ dan bermakna signifikan. Hasil ini menunjukkan bahwa makin tinggi nilai indeks diskriminasi maka makin tinggi pula indeks kesulitan soal dan begitupun sebaliknya. Hasil penelitian lain menemukan nilai korelasi positif lemah ( $\mathrm{r}=$ 0,3078 dan $\mathrm{p}=0,053$ ) namun tidak bermakna signifikan. ${ }^{17}$ Makin tinggi nilai indeks diskriminasi, makin rendah tingkat kesulitan soal. Indeks kesulitan (p) dan indeks diskriminasi (D) sering berhubungan secara terbalik kecuali pada kondisi yaitu nilai $\mathrm{D}$ terlalu rendah atau terlalu tinggi. Hubungan antara kedua indeks ini tidak linear, namun berbentuk dome-shaped. ${ }^{12}$ 
Pertanyaan ujian yang memiliki nilai $\mathrm{p}$ besar (soal mudah) memiliki kekuatan diskriminasi yang rendah, sedangkan pertanyaan dengan nilai $\mathrm{p}$ rendah dianggap merupakan diskriminator yang baik. Nilai dari indeks diskriminasi berkisar antara 0 sampai 1. Nilai indeks diskriminasi dapat juga negatif atau di bawah nol yang berarti mahasiswa dengan pemahaman rendah akan menjawab benar daripada mahasiswa dengan pemahaman sempurna. Hal ini mungkin disebabkan oleh sifat kompleks dari soal ujian sehingga memungkinkan mahasiswa dengan pemahaman rendah menjawab benar dengan cara menerka tanpa pemahaman yang sesungguhnya. Sementara itu, seorang mahasiswa yang pemahamannya sudah sempurna akan merasa penasaran dengan pertanyaan ujian yang mudah sehingga berpikir lebih rumit untuk menjawabnya dan seringkali malah salah menjawab. ${ }^{18}$

Evaluasi dari tiap soal MCQ sangat penting untuk melihat seberapa efektif soal ujian tersebut menilai pengetahuan mahasiswa berdasarkan nilai indeks diskriminasi dan indeks kesulitan soal ujian. Analisis MCQ pasca ujian membantu menilai kualitas masing-masing butir soal dan ujian secara keseluruhan. Analisis ini juga membantu mengidentifikasi materi pembelajaran yang masih belum dipahami dan yang membutuhkan perhatian besar dengan cara merubah atau memperbaiki metode pengajaran. Beberapa pertanyaan ujian yang tidak bagus dapat dimodifikasi atau dihilangkan dari soal ujian.

\section{Kesimpulan dan Saran}

Penelitian ini memberikan data mengenai karakteristik dasar ujian dan soalnya. Hasil penelitian menunjukkan bahwa sebagian besar soal ujian MCQ memenuhi kriteria indeks kesulitan acceptable dan indeks diskriminasi goodexcellent sehingga disimpulkan soal MCQ Blok Imunologi dan Neoplasma memiliki kualitas yang baik dan dapat disimpan dalam bank soal. Soal ujian dengan kriteria sangat mudah dan sulit menunjukkan kekuatan diskriminasi rendah, bahkan nilai indeks diskriminasi negatif ditemukan pada soal yang sulit. Soal MCQ dengan indeks diskriminasi rendah (poor) dan negatif mutlak harus dikaji dan direvisi ulang.

\section{Daftar Pustaka}

1. Kolte V. Item analysis of Multiple Choice Questions in Physiology examination. IJBAMR 2014; 4(4): 320-326.

2. Amin Z, Eng KH. Basic Medical Education. Singapore: World Scientific Publishing Co. Pte. Ltd, 2007.

3. Zaman A, Niwaz A, Faize, FA, Dahar MA. Analysis of multiple choice items and the effect of items sequencing on difficulty level in the test of Mathematics. Eur J of Soc Sci 2010; 17(1):61-67.

4. Boopathiraj C, Chellamani K. Analysis of test items on difficulty level and discrimination index in the test for research in education. IJSSIR 2013; 2(2):189-192.

5. Sayyah $\mathrm{M}$ et al., An item analysis of written multiple-choice question: Kashan University of Medical Sciences. Nurs Midwifery Stud 2012; 1(2):83-87.

6. Mitra N, Nagaraja H, Ponnudural G, Judson J. The levels of difficulty and discrimination indices in type A multiple choice question of pre-clinical semester 1, multidisciplinary summative tests. Int e-J-Sci Med Edu 2009; 3(1):2-7.

7. Mukherjee P, Lahiri SK. Analysis of Multiple Choice Questions (MCQs): Item and Test Statistics from an assessment in a medical college of Kolkata, West Bengal. IOSR-JDMS 2015; 12(12): 47-52.

8. Pande SS et al., Correlation between difficulty and discrimination indices of MCQs in formative exam in Physiology. SEAJME 2013; 7:45-50. 
9. Gajjar S, Sharma R, Kumar P, Rana M. Item and test analysis to identify quality Multiple Choice Questions (MCQs) from an assessment of medical students of Ahemdabad, Gujarat. Indian J Community Med 2014; 39:17-20.

10. Karelia BN, Pillai A, Vegada BN. The levels of difficulty and discrimination indices and relationship between them in four response type multiple choice questions of pharmacology summative tests of year II MBBS students. Ie JSME 2013; 6:41-46.

11. Patel KA, Mahajan NR. Itemized Analysis of Questions of Multiple Choice Question (MCQ) Exam. IJHSR 2013; 2:279-280.

12. Sim S-M, Rasiah RI. Relationship between item difficulty and discrimination indices in true/false-type multiple choice questions of a paraclinical multidisciplinary paper. Ann Acad Med Singapore 2006; 35 (2):67-71.

13. Eaves S, Erford B. Item analysis [cited 2016 Jan 5]. Available from: URL: http://www.education.com/reference/ article/item-analysis/.
14. Tarrant M, Ware J, Mohammed AM. An assessment of functioning and nonfunctioning distractors in multiplechoice questions: a descriptive analysis. BMC Med Ed 2014; 9: 40.

15. Hingorjo MR, Jaleel F. Analysis of onebest MCQs: the difficulty index, discrimination index and distractor efficiency. J Pak Med Assoc 2012; 62 (2):142-147.

16. El-Uri FI, Malas N. Analysis of Use of A Single Best Answer Format in An Undergraduate Medical Examination. Qatar Med J 2013; 1:3-6.

17. Shete AN, Kausar A, Lakhkar K, Khan ST. Item analysis: An evaluation of multiple choice questions in Physiology examination. J Contemp Med Edu 2015; 3(3):106-109.

18. Mehta G, Mokhasi V. Item Analysis of Multiple Choice Questions An Assessment of the Assessment Tool. IJHSR 2014; 4 (7):197-202. 